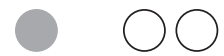

THE JOURNAL OF SOCIAL POLICY STUDIES

\title{
«ПУТЕВКА В ЖИЗНЬ» ДЛЯ «ТРУДНЫХ» ПОДРОСТКОВ? ВОЗМОЖНЫЕ СЦЕНАРИИ (РЕ)ИНТЕГРАЦИИ В СПЕЦИАЛЬНЫХ УЧРЕЖДЕНИЯХ
}

Тема статьи затрагивает проблему реинтеграции подростков, находящихся в конфликте с законом. Они обучаются в специальных учреждениях открытого и закрытого типов, использующих социально-поддерживающий подход в отношении своих воспитанников. Специальные учебно-воспитательные учреждения открытого типа работают, опираясь на законодательство, слабо разграничивающее деятельность учреждений открытого и закрытого типа. Имеют различный институциональный дизайн (разные режимы дня и внутренний распорядок в учреждениях, учебные программы, оснащение учебного заведения и территории). Кроме того, они представлены далеко не в каждом регионе, поэтому их функции по воспитанию и обучению подростков в конфликте с законом берут на себя другие образовательные учреждения, например, школы с адаптированными программами для детей и подростков с задержкой психического развития. Учреждения, в которых воспитываются и обучаются подростки в конфликте с законом реализуют ряд выездных программ, направленных на реинтеграцию подростков. Под реинтеграцией понимается кардинальная смена социальной среды и выстраивание стратегий приспособления к изменениям. Иными словами, специальные учреждения призваны помочь подростку выйти из-под влияния криминальных субкультур и включиться в повседневную жизнь. Поскольку деятельность учреждений различается по многим параметрам, формируется несколько вариативных сценариев реинтеграции. В статье рассматриваются сценарии реинтеграции подростков на примере специальных учреждений в разных регионах. Что обуславливает разные сценарии? Для ответа на этот вопрос применяется сценарный подход, который позволяет выявить ключевые сценарии, показывающие различия условий и практик в специальных

Ирина Викторовна Лисовская - к.с.н., научный сотрудник Центра молодежных исследований Национального исследовательского университета «Высшая школа экономики» в Санкт-Петербурге, Россия. Электронная почта: ilisovskaya@hse.ru 
учреждениях. Также используется стратегия кейс-стади. Отобрано три учреждения: два специальных учебно-воспитательных учреждения открытого типа (школа и училище) и одна школа, реализующая адаптированные программы. В исследовании применялись полуструктурированные интервью с воспитанниками 13-17 лет $(\mathrm{n}=21)$ и работниками учреждений $(\mathrm{n}=9)$, наблюдение. В результате выделяется три возможных сценария реинтеграции: сценарий, в котором нет реинтеграции, хаотичная реинтеграция, реинтеграция в производственные и иные городские сообщества. Различный институциальный дизайн учреждений, коммуникации подростков с педагогами и контроль в отношении подростков конструируют сценарии реинтеграции.

Ключевые слова: «трудные» подростки, реинтеграция, специальные учебно-воспитательные учреждения, сценарный подход, социальноподдерживающий подход

DOI: $10.17323 / 727-0634-2019-17-3-423-438$

В государственном секторе специального образования и социальной работы с подростками, находящимися в конфликте с законом, предусмотрены специальные учебно-воспитательные учреждения открытого и закрытого типов. Ряд учреждений является альтернативой учебно-воспитательным учреждениям, например, школы, реализующие адаптированные программы. В них работники обучают и воспитывают детей и подростков с задержкой психического развития. Среди воспитанников школы оказываются подростки в конфликте с законом, длительно не посещавшие общеобразовательную школу. Учреждения закрытого типа представляют собой принудительную воспитательную меру для детей и подростков, совершивших уголовные правонарушения. Будущие воспитанники направляются в них по решению суда, и, как правило, для несовершеннолетнего это является заменой лишению свободы. Соответственно, воспитанники ограничены в выходе из учебного заведения, в уставах учреждений прописана правомерность применения силы физического сдерживания к несовершеннолетним (Федеральный закон 1999).

Специальные учебно-воспитательные учреждения открытого типа в России появились в 2004 г., значительно позже, чем учреждения закрытого типа. Цель и миссия данных учебных заведений заключается в реализации особого психолого-педагогического подхода в отношении несовершеннолетних, находящихся в конфликте с законом или склонных к правонарушениям. Отличительная черта этих учебных заведений в том, что подросток не ограничен в праве свободного выхода из специальный школы или училища после окончания занятий. Учреждение открытого типа реализует специальные программы, направленные на реинтеграцию подростка в общество. Дети и подростки направляются в учебное заведение по рекомендации Психолого-медико-педагогической комиссии и Комиссии по делам 
несовершеннолетних и защите их прав за систематические пропуски школы, хулиганские проступки, совершение каких-либо правонарушений, за которые не наступает уголовная ответственность.

Специальные учреждения имеют различный институциальный дизайн: отличаются режимы дня и внутренний распорядок в учреждениях, учебные программы, оснащение учебного заведения и территории, а также подходы педагогов к воспитанию и контролю подростков, которых в педагогическом дискурсе называют «трудновоспитуемыми» или просто «трудными». В связи с этим конституируются вариации сценариев реинтеграции воспитанников специальных учреждений. В этой статье исследуется, какие существуют сценарии реинтеграции подростков в конфликте с законом силами организаций государственного сектора на примере специальных учреждений в разных регионах. Какие условия позволяют говорить об этих различных сценариях?

\section{Специальные учреждения для подростков В конфликте С законом В международном контексте}

Существует два основных подхода к коррекции противоправного поведения в ювенальной юстиции: восстановительный (восстановительное правосудие) и карательный (Головизнина 2007). Наиболее успешным часто называется восстановительный подход (см.: Karp et al. 2001; Tyler 2006). Наименее успешным, соответственно, можно считать карательный подход в отношении коррекции противоправного поведения. Многочисленные исследования подтверждают, что применение заключения в отношении несовершеннолетнего способствует дальнейшему рецидиву, социализации в криминальной субкультуре, социальной эксклюзии (Маколи 2008; Simon 2007; Cullen 2007; Koehler et al. 2013; Taylor et al. 2013).

В исследовании российских колоний для несовершеннолетних Мэри Маколи особо подчеркивается опасность заключения несовершеннолетнего. Исследовательница противопоставляет санкции и наказания в виде лишения свободы подходу социального государства (социально-поддерживающий подход), который способствует ресоциализации, реинтеграции подростка в общество (Маколи 2008). На практике социально-поддерживающий подход реализуется не только в системе государственной социальной поддержки или ювенальной юстиции, но и в виде терапевтических кружков, творческих сообществ, которые способствует успешной реинтеграции. Например, продуктивны в поддерживающей деятельности некриминальные сообщества во главе с успешными людьми, имеющими опыт судимости или заключения (Maruna 2001; McNeill 2012). Социально поддерживающий подход можно считать формой восстановительного правосудия.

В России не существует единой и непротиворечивой ювенальной юстиции, а наиболее распространенным остается именно карательный подход 
в отношении несовершеннолетних (Muravyeva 2017). Тем не менее имеющиеся учреждения открытого типа, реализующие социально-поддерживающий подход, являются единственным примером работы в направлении более гуманных практик реинтеграции, хотя их число очень ограничено.

Российские исследователи отмечают отсутствие адекватного законодательства, которое бы раскрывало функции и полномочия специальных учебно-воспитательных учреждений разных видов, а также причины, по которым подростки могут направляться в учреждения открытого типа (Сидоров, Бондаренко 2012). Кроме того, ученые описывают воспитанников, как подростков педагогически запущенных, имеющих хронические заболевания, находящихся в социально-опасном положении в семье и в трудной жизненной ситуации. В целом можно отметить большой пробел и ограниченность социологических исследований учреждений, использующих восстановительный подход к подросткам, преступившим закон.

\section{Сценарный подход \\ В исследовании реинтеграции подростков}

Когда человек кардинально меняет социальную среду, адаптируется к новым условиям жизни, включается в другое общество, то для понимания этих процессов часто применяется термин «реинтеграция». В широком смысле- это процесс приспособления мигрантов при возвращении домой, бывших заключенных к свободной жизни (Burnett 2009; Arowolo 2000). Индивид как будто выпал на определенный срок из привычного контекста, а, вернувшись, пытается приспособиться к изменившимся условиям, снова включиться в социальную жизнь (Бредникова 2017). Этот же термин можно применить к подросткам, которые социализировались в уличной или криминальной субкультуре, имели постоянные конфликты с законом, проблемы в семье, трудную жизненную ситуацию. В этом смысле они не интегрированы в общество.

С другой стороны, также под реинтеграцией понимаются отдельные социальные программы, инициативы гражданского общества или государства, направленные на адаптацию подростков- их ориентацию в городе и участие в жизни сообществ, повседневность молодежных культур, активистских инициативах (Ward, Maruna 2007; Burnett, Maruna 2006). В этом случае специальные учебно-воспитательные учреждения создают экскурсионные программы, образовательные туры, вовлекают воспитанников в волонтерство и другие практики.

Сценарный подход позволяет определить сценарии реинтеграции воспитанников для разных специальных учреждений. Понятие ключевого сценария ввела Шерри Ортнер. Под данным термином ею понимаются культурные коды и шаблоны поведения индивидов в разных обществах (Ortner 1973). Как правило, данный подход используется в исследованиях миграции (напр., Бредникова 2017; Лернер и др. 2009), поскольку он позволяет определить вариации жизни 
мигрантов в контекстах разных культур и обществ. Эту концепцию актуально использовать и для исследований реинтеграции бывших заключенных или, в моем случае, так называемых «трудных» подростков. Поэтому в статье на примере трех кейсов выделяются условия социальной среды внутри учреждения и особенности коммуникаций между воспитанниками и работниками, чтобы обозначить текущие сценарии реинтеграции.

Для исследования выбран метод кейс-стади, поскольку для того, чтобы определить варианты сценариев реинтеграции необходимо всесторонне проанализировать каждый отдельный случай. Исследование отдельных кейсов позволяет сравнивать другие похожие случаи, что актуально в изучении условий, которые формируют разные сценарии (Романов 2005). В разных регионах и городах отобраны три специальных учреждения, использующие социальноподдерживающий подход в отношении воспитанников, совершивших правонарушения: школа, реализующая адаптированные программы (VII вида) в малом городе; учебно-воспитательное учреждение профессиональное училище открытого типа в крупном городе; учебно-воспитательное учреждение общеобразовательная школа открытого типа в городе федерального значения. Для удобства кейсы обозначены краткими значениями: кейс 1 школа, кейс 2- профучилище, кейс 3 - специнтернат. Выбор школ осуществлялся исходя из возможностей доступа, максимально различных условий социальной среды и места расположения, наличия разных видов учреждений государственного сектора, работающих с подростками в конфликте с законом. Наименования городов скрыты, название может выдать учреждение, поскольку зачастую оно единственное в городе или даже федеральном округе.

Основным исследовательским методом выбрано полуструктурированное интервью с элементами биографического с воспитанниками учреждений в возрасте 13-17 лет, учителями и сотрудниками. В двух специальных учебно-воспитательных учреждениях обучаются только мальчики, в школе, реализующей адаптированные программы, обучаются и мальчики, и девочки. Было собрано 30 интервью: 21 с подростками, девять с работниками учреждений. В двух кейсах интервью проводились только с юношами, из-за гендерного разделения обучения в образовательном учреждении. В одном из кейсов три интервью с девушками, четыре интервью с юношами. Дополнительным методам в исследовании является наблюдение. Интервью с несовершеннолетними проводились с согласия администрации учебных заведений и законных представителей учеников, затем анонимизировались, особенности лексики сохранены.

\section{Коммуникация между воспитанниками и работниками в специальных учреждениях}

Школа находится на самой окраине малого города рядом с сельской местностью. На территории школы- заброшенная теплица, выкупленная 
частным предпринимателем, территория находится в запустении. Однако внутри школы развита инфраструктура, которой «завидуют» другие учебные заведения со слов работников учреждения:

Если в других школах [специальное оборудование и оснащение покупается] за счет родительских средств, то здесь идет все, вплоть, я говорю, и автобус свой школьный, и все оборудование поставляется, тратятся деньги-миллионы. Ну, как бы многие школы нам завидуют, что ни че себе! Мы пытаемся где-то что-то купить, а вам все это [бесплатно] идет! (Завуч, ж., 49 лет)

Несмотря на то, что в школе хорошая инфраструктура, взаимоотношения между учителями и учениками напряженные. Коммуникация между ними построена исключительно на попытках принудить к обучению, внеучебные взаимоотношения практически отсутствуют:

Она [учитель] подошла короче, я жвачку... ну я как бы жвачку хотел, как бы проглотить... И все я... Три раза пожевал, пожевал и выплюнул. Сразу она короче подошла... учитель короче... тряпка у нее. Чуть было меня ей не накормила. Я отвернулся короче (ученик 9 класса, м., 15 лет).

Нередки случаи стигматизации учеников: «Ну она меня бесит. Недородыши [обращение учителя к ученикам]. Вот еще одно слово скажу: суки» (ученица 8 класса, ж., 14 лет). В школе не формируются какие-то иерархии управления классом среди учащихся, нет интеграции в сообщества по интересам или секции в школе.

Другой кейс-профучилище. Большинство воспитанников-приезжие из отдаленных селений и поселков, проживают в общежитии. Специальное учреждение ориентировано на спортивное и производственное развитие подростков, созданы условия для работы многих секций (мини-футбол, теннис, бокс и самбо, производственные кружки), арендованы площадки в близлежащих учебных заведениях (компьютерный класс для сетевых игр). Тем не менее в училище существуют материальные проблемы:

Вот сейчас по лицензии мы можем [открыть] любую профессию, но под любую профессию дидактический материал надо, пособие надо. Вот, допустим, вот сейчас... Хорошо, что опять же мы с воинской частью договорились- они нам отдают автокласс. Мы потом проедем по свалкам, наберем двигателей, опять же будем просить-кланяться [просить разрешения у других образовательных учреждений отдать списанное оборудование для оснащения учебной мастерской училища] вот так вот. И мы попробуем открыть «слесарь по ремонту автомобилей», что интересно детям (завуч по х/ч, ж., 55 лет).

Работники учреждения учитывают особенности возраста своих воспитанников, не вступают с ними в конфликты, в определенной степени дают свободу. Таким образом, они постепенно приобщают учеников к повседневной жизни и режиму внутри специального учреждения. Один 
из методов- добровольное участие в любых возможных секциях и мероприятиях, постепенное погружение без принуждения:

В общем это не кружок- это отряд [волонтерский], в общем-то... но он у нас отряд, скажем так, [вздыхает] учитывая специфику ребят ...мы его не делаем, как скажем, застывшим, потому что ...эээ... сегодня, вот, одна группа товарищей они же у нас... ээээ... де... не дети, ребята, подверженные даже метеоусловиям [перемена настроения или ухудшение самочувствия воспитанника]. . < ..> Поэтому мы не делаем так, что ты вот записался и ты вот обязательно должен туда ходить, ты будешь! (завуч, ж., 52 года).

Воспитанники постепенно интегрируются в повседневную жизнь учреждения через приобретение определенных ролей или членства в небольших группах. Подростки наделяются ответственностью за результат, особенно лидеры сообществ. Происходит конструирование иерархий, образуются спортивные, профессиональные, волонтерские группы по интересам.

Третий кейс, специнтернат, находится в городе федерального значения, территория школы ограждена высоким забором с контрольно-пропускным пунктом на входе. Территория ухоженная: плитка и клумбы, площадки для игр и развлечений. Внутри школы сделан качественный ремонт, по коридорам развешаны картины, стоят мягкие диваны, оборудованы комнаты психологической разгрузки, спортивный зал с тренажерами. Тем не менее ощущается изоляция от внешнего мира. До конца рабочего дня учреждение закрыто для учеников- они не могут свободно выходить за территорию, даже если проживают в городе. Воспитатели ссылаются на большую ответственность за воспитанников:

Мы за забор их выпускаем, и это сразу считается экскурсия. То есть нельзя так просто взять и выйти в парк. Нужно всех детей проинструктировать о безопасности. Напечатать приказ за подписью директора (воспитатель, ж., 29 лет).

Внутри школы коммуникация с учениками построена на индивидуальном подходе: «Самая эффективная мера - это способ или что вы там сказали... средство... это просто их любить и относиться к ним с любовью» (воспитатель, ж., 55 лет). Подростки, оказываясь в учреждении, рефлексируют о прошлых местах обучения, сравнивая педагогов и стили воспитания. В нарративах интервью прослеживается сравнение школы с «раем»:

Ну это рай, да, как бы, тут подбирают специальных учителей для учеников, чтобы не было никакой жесткости. Тута даже никаких домашних заданий не задают, чтобы не напрягать учеников, тут всё есть... <..> Тут говорят при пересдаче «пожалуйста» подойди, пересдай, а там [в другой школе] если не придешь, всё двойку в четверти и будет нафиг со школы и всё (ученик 8 класса, м., 14 лет). 
С помощью мягкого участливого отношения со стороны учителей к воспитанникам, они контролируют практически все стороны жизни ученика, сопровождают на секциях и уроках, экскурсиях, лишая самостоятельности. Режим дня плотный, все расписано до минут. Посещение секций сводится к обязанности занять чем-либо время. Вся инициатива исходит «сверху», в результате чего не образуется сложных иерархий в коллективе сверстников.

Мы видим три разных примера того, как устроен контроль со стороны работников за воспитанниками, коммуникация с ними, режимы и среда внутри учебных заведений. Все учреждения различны. В первом примере коммуникация основана на стигматизации и оскорблении учеников, но внутри развита инфраструктура, во втором примере, наоборот, в учреждении есть потребности в совершенствовании оснащения мастерских, но работники находят общий язык с воспитанниками путем договора. В третьем примере на фоне общего достатка внутри учебного заведения, подростки оказываются лишены некоторых свобод, личного свободного времени, весь день расписан по минутам, а педагоги коммуницируют с воспитанниками, проявляя повышенную заботу и авторитарность одновременно. То, каким образом строится коммуникация с воспитанниками, как устроен быт в учебном заведении и инфраструктура, влияет на коммуникативные практики учеников за пределами учреждения.

\section{Реинтеграция подростков в общество}

В малом городе, где расположена школа, популярностью у молодежи пользуются следующие досуговые организации: ботанический сад, дворец культуры, кинотеатр, две молодежных пиццерии, большое количество питейных заведений. Из наблюдений: молодежь проводит большую часть времени на улице, даже в зимний период, поскольку число досуговых, развлекательных и иного профиля организаций ограничено. Образовательные и развлекательные организации города стигматизируют школу как непрестижное учебное заведение. Также они ограничивают контакты со специальной школой путем сокращения числа посещений развлекательных городских и межшкольных досуговых мероприятий воспитанниками. Соответственно, образовательные и некоторые культурные организации оказываются закрытыми для них. Сами педагоги, за редким исключением, используют свои связи и знакомства для вывоза воспитанников на мероприятия в другие организации, пытаются действовать с помощью прямого договора о посещении организаций, секций, что в итоге не приводит к успешному результату:

Да, пугают! [Учителя других школ своих учеников переводом в школу с адаптированными программами] Даже, вот, «школа дураков». Дети, конечно, если да, сопоставить-в основной массе, конечно, дети отличаются 
своей этой интеллектуальной запущенностью. Они не особо там умные... $<\ldots$.. $>$ То есть... ну по возможности стараемся их куда-то вклинить, но, как правило, нас город не зовет, потому что... (завуч, ж., 49).

Многие ученики еще до обучения в школе состояли в криминальной субкультуре с общим бюджетом- общаком, созданным криминальными авторитетами города для нужд криминальных организаций. Криминальная структура в городе имеет строгую иерархию: в каждом дворе есть смотрящие или, как их называют подростки, «дворовые». Они выполняют функции замещения основного лидера криминальной структуры в каждом районе города- следят за соблюдением воровского закона и собирают деньги с участников структуры для нужд общака:

Ну, с дворовыми там. <...> Ну там... тоже помогают. Ну они смотрят за... У нас в каждом районе они смотрят. За каким-то один человек смотрит за каким-то микрорайоном. Ну все. А там... как бы это называется «общак». Они если в трудную там что-то... час там... ну, в каждую минуту трудную они стараются помочь детдомовским (ученик 8 класса, м., 14 лет).

Важный элемент субкультуры- это взаимная поддержка. Подростки больше всего ценят покровительство, которое дает им криминальная организация взамен на выполнение мелких поручений. Во всех интервью можно выделить фразы «он помогает», «защищает», «всегда поможет», «вытащит», характерные для описания «дворовых», которые смотрят за районом.

В этом кейсе разрыва связей с криминальной организацией не происходит. Дети, которые имеют трудную жизненную ситуацию, сталкиваются с унижениями в школе, внедряются в криминальную структуру глубже, например, совершают магазинные кражи, зарабатывая себе статус в криминальной структуре. Реинтеграцией в этом случае можно было бы считать разрыв с криминальным миром, включение в какие-либо городские, активистские некриминальные сообщества.

Во втором кейсе другая ситуация. Учебное заведение расположено в крупном городе, со значительным количеством производственных кластеров, досугово-развлекательных организаций, развит бизнес. Каким образом подростки включаются в повседневную жизнь крупного города? Как уже отмечено, внутри училища формируются сообщества по интересам и соответствующие иерархии, а педагоги этому способствуют, используя метод договора с воспитанниками. Юноши из профессиональных групп интегрируются в городские профессиональные сообщества. Они направляются учебным заведением на ярмарки по результатам конкурса на лучшие столярные изделия. Участие в них помогает заводить новые контакты из профессиональной и производственной среды. Подростки организуют свою повседневность через рабочие практики внутри училища и за его пределами. Педагоги помогают им в этом, используя собственные знакомства и связи, рекомендуют их на работу: 
Вот Гришка есть, он на первом курсе, вполне нормальный, да, Захлебов, который вполне рассуждает, которому надо работать. И мне уже подходит: «Вы ж меня устроите на производственную практику, где там и денежку заработать?». Я говорю: «Гриш, не вопрос. Мы попробуем это». Идем, вот так кланяемся, договариваемся в автослесарных всяких мастерских: «Возьмите наших пацанов на работу!» (мастер производственного обучения, ж., 50 лет).

Иными словами, учреждение становится проводником в городские производственные кластеры, профессиональные ярмарки, спортивные городские команды. Профучилище интегрирует воспитанника в производственные секции внутри самого училища. Затем некоторые подростки изъявляют желание быть включенным в производство в общем городском пространстве. Учреждение подбирает объекты, через которые можно устроить воспитанников на работу еще во время обучения, включить в городские культуры, например, волонтерские городские сообщества. Данный процесс осложняется барьерами восприятия стигмы воспитанника специального учреждения:

Как это [стигматизация «девиантные подростки» в прежнем наименовании Профучилища] повлияет? Ну, надпись может повлиять как бы тем, что будут относиться с осторожностью, могут на работу не взять, либо, когда возьмут на работу, будут как бы смотреть, ну, и, наверное, любой косяк будут списывать (студент 1 курса специального училища, м.,16 лет).

Специальное учебно-воспитательное учреждение общеобразовательная школа в мегаполисе имеет отличный опыт от двух предыдущих кейсов. Политика учреждения такова, что для своих воспитанников подбираются самые инновационные площадки для экскурсий, преследуется цель максимального включения в молодежные современные площадки города, но при этом не ослабевает контроль за воспитанниками, в том числе ограничения на самовольный выход в город для тех, кто живет в общежитии при школе.

Экскурсионная программа в школе заключается в плановом посещении четыре раза в неделю разных организаций: музеев, театров, спортивных мероприятий, досуговых центров. Также экскурсии являются методом контроля за успеваемостью: «На экскурсии они всегда хотят ехать, этими экскурсиями я их всегда шантажирую! [смеется]. Что, если ты вот это не сделаешь, то никакой экскурсии, ть что!» (воспитатель, ж., 29 лет). При этом экскурсии подбираются на вкус педагогов из соображений самых модных и креативных городских пространств, которые могут увлечь подопечных. Дивиденды в виде дорогостоящих экскурсий стимулируют подростка не протестовать, исполнять ролевые предписания. Потребление города происходит хаотично, без формирования длительных постоянных интересов и идентификаций. 
Находясь в учреждении, подростки выполняют требуемые роли, при выходе из учреждения роли автоматически сбрасываются. Так, ученики, которые проживают в городе, после выхода из учреждения вечером могут побыть в своей дворовой компании и поучаствовать в ее жизни. Некоторые играют в спортивные игры, курят и слушают музыку на стадионе в компании сверстников, а кто-то участвует в территориальных войнах- «стрелках»:

Двести на двести человек. Двести от них и двести человек от нас. А нас всего 100 с чем-то. <..> Мы сидим только в своем районе- мы в другие не ходим, не хотим соваться, потому что у нас как раз какая-то потасовка, то, что 200 на 200, произошла из-за того, то, что мы пришли в другой район, немножечко посидели где-то полчаса и нам потом уже написали, то, что мы заняли чужую точку. В итоге нам забили вот эту стрелу (ученик 9 класса, м.,15 лет).

В данном случае реинтеграция хаотична, т.е. потребление города или спортивных, досуговых, образовательных и развлекательных организаций учениками школы происходит выборочно и в основном одноразово, под присмотром педагогов. Если во втором примере, наоборот, работники направляли подростка, а затем он включался самостоятельно в какуюлибо культуру или секцию и имел опыт длительного участия в ней, то в третьем случае такого не происходит. Здесь подросток хаотично включается в разные активности за пределами школы, но в отсутствие контроля и сопровождения со стороны учителей этого не делает.

\section{Заключение: сценарии реинтеграции}

На примере рассмотренных кейсов мы видим три разных метода контроля, коммуникации с подростками в специальных учреждениях и различные способы их включения в повседневную городскую жизнь. Сценарии реитенграции- это модели поведения и коммуникации воспитанников специальных учреждений (открытого типа, которые формально не изолированы) в городе, способы и опыт их включения в какие-либо (не)криминальные городские сообщества.

В первом примере описана коммуникация, основанная на стигматизации, систематических оскорблениях, физической силе, принуждении к обучению. Такой пример можно назвать формальным контролем, когда работники всеми силами пытаются выполнить свои функции, применяя в том числе физическую силу. Несмотря на то, что учреждение располагает значительными ресурсами и инфраструктурой, учителя школы не могут справиться с подростками, превышают свои должностные обязанности. Учителя не используют свои связи, чтобы налаживать контакты с организациями города для дополнительного досуга и проведения выездных мероприятий, поэтому, такого рода мероприятия практически отсутствуют. Подростки являются членами криминальных объединений и остаются ими, 
даже когда попадают в учебное заведение, выхода из них не происходит. Это сценарий, в котором отсутствует процесс реинтеграции, как включения воспитанника в новую социальную среду и адаптацию в ней.

Во втором примере- профессиональное училище- внутренняя инфраструктура развита, но ресурсы ограничены, учреждение не имеет финансовых возможностей открывать новые специальности. Педагоги договариваются и советуются с воспитанниками, находят с ними общий язык и достигают компромисса при обсуждении острых и деликатных вопросов. Такой метод можно назвать демократичным контролем, поскольку существуют формы договора, учитывается мнение воспитанников. Создаются сообщества по интересам, участие в которых является добровольным. Таким образом формируются интересы и идентификации воспитанников с каким-либо ремеслом. Затем педагоги, используя собственные связи, помогают включаться в спортивные, производственные, активистские сообщества. Воспитанник получает длительный опыт работы или другой деятельности. В этом случае конструируется сценарий реинтеграции в производственную и иную некриминальную деятельность.

В третьем примере мы рассматриваем вид коммуникации с воспитанниками, который основан на авторитарности. Ученики соблюдают правила режима, получают за это похвалу, участливое отношение к себе. Учреждение характеризуется достатком, развитой инфраструктурой, ученики пользуются ресурсами учреждения, но лишены свободы выхода за территорию во время учебного дня для проживающих в семьях, полное ограничение свободного выхода для тех, кто проживает в школьном общежитии. Педагоги договариваются с городскими организациями об экскурсиях, вывозят детей, но сама экскурсионная программа- часть режима дня, педагоги выбирают экскурсии для воспитанников сами. Подростки каждый раз посещают новые места, длительных увлечений не формируется. После учебного дня, расписанного по минутам, ученик уходит домой и проводит свое свободное время «во дворе». Досуг некоторых ребят построен на совершении нарушений общественного порядка в компании друзей. Данный пример можно назвать хаотичной реинтеграцией- непоследовательным потреблением города и различных развлекательных, досуговых, образовательных, спортивных организаций без формирования опыта длительного посещения и идентификаций с новыми ролями и увлечениями.

Особо важно отметить роль городской среды в конструировании этих сценариев. Город в данном случае не играет определяющую роль, только задает условия, в которых учреждение функционирует. Данные сценарии выделены как некоторые из широкого спектра возможных. Дальнейшее исследование для полноты картины должно включать еще один кейс: организацию из сектора гражданского общества.

\section{Список источников}

Бредникова О.Е. (2017) (Не)возвращение: могут ли мигранты стать бывшими? Этнографическое обозрение, (3): 32-47. 
Головизнина М.В. (2017) Преступность несовершеннолетних, ювенальная юстиция и восстановительное правосудие в Италии. Вопросы ювенальной юстиции, (2): 44-47.

Лернер Ю., Рапопорт Т., Ломски-Федер Э. (2009) Русскоязычные студенты в израильском университете: как работает «этнокультурный сценарий» советских евреев в эмиграции. Диаспоры, (2): 62-90.

Маколи М. (2008) Дети в тюрьме. Москва: ОГИ.

Романов П.В. (2005) Стратегия кейс-стади в исследовании социальных служб. Сочиологические исследования, (4): 101-110.

Сидоров Н.Р., Бондаренко И.Н. (2012) Исследование социально-психологических особенностей воспитанников специальных школ открытого типа. Прикладная юридическая психология, (2): 63-73.

Федеральный закон (1999) Об основах системы профилактики безнадзорности и правонарушений несовершеннолетних № 120-ФЗ от 24.06.1999 г.

Arowolo O. O. (2000) Return Migration and the Problem of Reintegration. International Migration, 38 (5): 59-82.

Burnett R. (2009) Post-Corrections Reintegration: Prisoner Resettlement and Desistance from Crime. In: J. Adler, J. Gray (eds.) Forensic Psychology: Concepts, Debates and Practice. London: Willan:540-560.

Burnett R., Maruna S. (2006) The Kindness of Prisoners: Strengthsbased Resettlement in Theory and in Action. Criminology and Criminal Justice, 6 (1): 83-106.

Cullen F. T. (2007) Make Rehabilitation Corrections' Guiding Paradigm. Criminology \& Public Policy, 6 (4): 717-727.

Karp D. R., Breslin B. (2001) Restorative justice in school communities. Youth \& Society, 33(2): 249-272.

Koehler J. A., Lösel F., Akoensi T.D, Humphreys D. K. (2013) A Systematic Review and Meta-Analysis on the Effects of Young Offender Treatment Programs in Europe. Journal of Experimental Criminology, 9 (1): 19-43.

Maruna S. (2001) Making Good: How Ex-convicts Reform and Rebuild Their Lives. Washington: American Psychological Association Books.

McNeill F. (2012) Four Forms of 'Offender' Rehabilitation: Towards an Interdisciplinary Perspective. Legal and Criminological Psychology, 17 (1): 18-36.

Muravyeva M. G. (2017) Juvenile Justice in Russia. In: C. J. Schreck (ed.) Wiley Encyclopedia of Juvenile Delinquency and Justice. Hoboken: Wiley. Available at: https://doi. org/10.1002/9781118524275.ejdj0194 (accessed 5 August 2019).

Ortner Sh. (1973) On Key Symbol. American Anthropologist, 75 (5): 1338-1346.

Simon J. (2007) Governing Through Crime: How the War on Crime Transformed American Democracy and Created a Culture of Fear. Oxford: Oxford University Press.

Taylor I., Walton P., Young J. (2013) The New Criminology: For a Social Theory of Deviance. London: Routledge.

Tyler T.R. (2006) Restorative Justice and Procedural Justice: Dealing with Rule. Journal of Social Issues, 62 (2):307-326.

Ward T., Maruna S. (2007) Rehabilitation: Beyond the Risk Paradigm. London: Routledge. 
Irina Lisovskaya

\section{A 'START IN LIFE' FOR TROUBLESOME KIDS? POSSIBLE SCENARIOS OF REINTEGRATION IN THE CONTEXT OF SPECIAL INSTITUTIONS}

This article focus on the reintegration of troublesome adolescents into society, who are educated in special need institutions (special open-type institutions in Russia). These institutions use a social welfare approach. Open-type institutions have various designs; moreover, they are not represented in every region. Special institutions implement a select number of field programs aimed at reintegrating adolescents. Reintegration is a radical change in the social environment of adolescents and offers strategies for adapting to change. Special institutions aim to help the teenager escape from the influence of criminal subcultures and integrate into everyday city life. A variety of scenarios for adolescent reintegration are explored in this paper. What scenarios of reintegration of adolescents are in conflict with the law in the case of special institutions? What conditions construct reintegration scenarios? The scenario approach is used to answer these questions. The scenario approach identifies key scenarios and shows differences in conditions and practices in institutions and adolescent behaviours. A case study strategy is also employed. There are two special institutions of an open type (school and school) in a large and federal city; a school that implements adapted programs in a small town. The main research methods behind this research are semistructured interviews with pupils aged thirteen to seventeen $(\mathrm{n}=21)$ and employees of institutions $(\mathrm{n}=9)$, as well as observation and analysis of documents. Three possible reintegration scenarios are identified. The first is when there is no reintegration, the second is 'chaotic' reintegration, and the third is reintegration into industrial and other urban communities. Scenarios construct various situations and conditions, including control over adolescents, communication between adults and adolescents.

Key worlds: troublesome adolescent, reintegration, special need institutions, scenario approach, social welfare approach

DOI: 10.17323/727-0634-2019-17-3-423-438

\section{References}

Arowolo O. O. (2000) Return Migration and the Problem of Reintegration. International Migration, 38 (5): 59-82.

Irina V. Lisovskaya- PhD, researcher in Centre of Youth Studies, National Research University 'Higher School of Economics', St. Petersburg, Russian Federation. Email: ilisovskaya@hse.ru 
Brednikova O.E. (2017) (Ne)Vozvrashchenie: mogut li migranty stat' byvshimi? [The (Non-) Return: Can Migrants Become Former Migrants?]. Etnograficheskoe obozrenie [Ethnographic Survey], (3):32-47.

Burnett R. (2009) Post-Corrections Reintegration: Prisoner Resettlement and Desistance from Crime. In: J. Adler, J. Gray (eds.) Forensic Psychology: Concepts, Debates and Practice. London: Willan:540-560.

Burnett R., Maruna S. (2006) The Kindness of Prisoners: Strengths-based Resettlement in Theory and in Action. Criminology and Criminal Justice, 6 (1): 83-106.

Cullen F. T. (2007) Make Rehabilitation Corrections' Guiding Paradigm. Criminology \& Public Policy, 6 (4): 717-727.

Federal Law (1999) Ob osnovakh sistemy profilaktiki beznadzornosti i pravonarusheniy nesovershennoletnikh [On the Basics of the System for the Prevention of Child Neglect and Juvenile Delinquency] N 120 from 24 June 1999.

Goloviznina M.V. (2017) Prestupnost' nesovershennoletnikh, yuvenal'naya yustitsiya i vosstanovitel'noe pravosudie v Italii [Juvenile Delinquency, Juvenile Justice and Restorative Justice in Italy]. Voprosy yuvenal'noy yustitsii [Juvenile Justice Issues], (2):44-47.

Karp D. R., Breslin B. (2001) Restorative Justice in School Communities. Youth \& Society, 33 (2): 249-272.

Koehler J. A., Lösel F., Akoensi T. D, Humphreys D. K. (2013) A Systematic Review and Meta-Analysis on the Effects of Young Offender Treatment Programs in Europe. Journal of Experimental Criminology, 9 (1): 19-43.

Lerner J., Rapoport T., Lomski-Feder E. (2009) Russkoyazychnye studenty v izrail'skom universitete: kak rabotaet 'etnokul'turnyy stsenariy' sovetskikh evreev v emigratsii [Russian-speaking Students at an Israeli University: How the 'Ethnocultural Scenario' of Soviet Jews Works in Exile]. Diaspory [Diasporas], (2): 62-90.

Maruna S. (2001) Making Good: How Ex-convicts Reform and Rebuild their Lives. Washington: American Psychological Association Books.

McAuley M. (2008) Deti v tyur'me [Children in Prison]. Moscow: OGI.

McNeill F. (2012) Four Forms of 'Offender' Rehabilitation: Towards an Interdisciplinary Perspective. Legal and Criminological Psychology, 17 (1): 18-36.

Muravyeva M. G. (2017) Juvenile Justice in Russia. In: C. J. Schreck (ed.) Wiley Encyclopedia of Juvenile Delinquency and Justice. Hoboken: Wiley. Available at: https://doi. org/10.1002/9781118524275.ejdj0194 (accessed 5 August 2019).

Ortner S. (1973) On Key Symbols. American Anthropologist, 75 (5): 1338-1346.

Romanov P. V. (2005) Strategija kejs-stadi v issledovanii social'nyh sluzhb [The Case Study Strategy for Social Services Research]. Sociologicheskie issledovanija [Sociological Studies], (4): 101-110.

Sidorov N.R., Bondarenko I. N. (2012) Issledovanie sotsial'no-psikhologicheskikh osobennostey vospitannikov spetsial'nykh shkol otkrytogo tipa [Study of the Socio-psychological Characteristics of Pupils of an Open Type School]. Prikladnaya yuridicheskaya psikhologiya [Applied Legal Psychology], (2): 63-73. 
Simon J. (2007) Governing Through Crime: How the War on Crime Transformed American Democracy and Created a Culture of Fear. Oxford: Oxford University Press.

Taylor I., Walton P., Young J. (2013) The New Criminology: For a Social Theory of Deviance. London: Routledge.

Tyler T. R. (2006) Restorative Justice and Procedural Justice: Dealing with Rule. Journal of social issues, 62 (2):307-326.

Ward T., Maruna S. (2007) Rehabilitation: Beyond the Risk Paradigm. London: Routledge. 